\title{
Biomarkers for Precision Treatment in Gastric Cancer
}

\author{
Angelica Petrillo ${ }^{a, b} \quad$ Elizabeth C. Smyth ${ }^{c}$

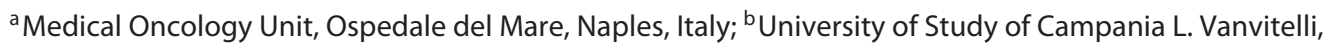 \\ Naples, Italy; 'Cambridge University Hospitals NHS Foundation Trust, Cambridge, UK
}

\section{Keywords}

Microsatellite instability . Programmed death ligand 1 . ctDNA · Human epidermal growth factor receptor 2 . Prognostic factors

\begin{abstract}
Background: Gastric cancer (GC) is one of the most lethal cancers worldwide. Although GC was historically considered a single entity within the organ of origin, nowadays it is acknowledged that GC represents a heterogeneous disease. Nevertheless, in this field there is still a lack of biomarkers able to guide the choice of the best treatment options for each patient. This review aims to summarize the prognostic and predictive biomarkers evaluated in GC and their role as a guide for treatment for precision medicine. Summary: Human epidermal growth factor receptor 2 overexpression represents the only predictive molecular biomarker validated in GC, while its prognostic role is still controversial. Microsatellite instability and Epstein-Barr virus status are promising for prediction of the response to immunotherapy. The role of other biomarkers (ctDNA, programmed death ligand 1 [PDL1], and TMB), as well as the practical application of molecular classifications, requires further evaluation before use in clinical practice. 18-FDG-PET scan could be useful as a predictive tool in non-metastatic GC patients receiving a perioperative approach. Finally, the tumor microenvironment may have an evolving role in the future. Key Messages: GC is a heterogeneous disease and targeted approaches are needed. The finding of prognostic and predictive factors is a hot topic in the field of GC personalized medicine.
\end{abstract}

(c) 2020 S. Karger AG, Basel

\section{Introduction}

Gastric cancer (GC) represents one of the most lethal cancers worldwide [1], primarily due to late diagnosis, especially in non-Asian countries. According to international guidelines [2] non-metastatic GC treatment is based on a perioperative approach with chemotherapy (FLOT schedule) [3] and surgery. For patients with metastatic GC, chemotherapy - with or without targeted agents - was for many years the only available treatment in this setting. Recently, immune checkpoint blockade has been approved in several countries for patients with chemorefractory GC [4]. Although GC has always been considered a single entity, nowadays it is acknowledged that it represents a heterogeneous disease, in addition to encompassing esophageal adenocarcinoma.

In GC, several molecular classifications have been developed over the last decades in an attempt to select molecular alterations, which might act as a driver for each subtype [5]. Recently, The Cancer Genome Atlas (TCGA) performed a comprehensive analysis and distinguished the following 4 subtypes of GC: Epstein-Barr virus (EBV) positive ( $9 \%$ of GC), microsatellite instability (MSI; $21 \%$ ), genomically stable (GS; 20\%), and chromosomal instability (CIN; 50\%). Each subtype is associated with different features and it is enriched for selected molecular abnormalities with some overlap [6]. These findings have potentially important therapeutic implications, which could increase the availability of targeted therapies against the specific key pathways driving the tumor in individual patients. Additionally, the Asian Cancer Research Group (ACRG) proposed a molecular classification based on 
molecular and genetic alterations in GC. According to the ARGC classification, the following 4 groups of GC exist: MSI (23\%), microsatellite stable with intact p53 (MSS/ TP53-; 36\%), microsatellite stable with p53 mutations (MSS/TP53+;26\%), and microsatellite stable with epithelial-mesenchymal transition (MSS/EMT; 15\%) [7]. Both classifications reported different outcomes for each subgroup. In particular, the ACRG showed that MSI had a better prognosis and MSS/EMT had a worse prognosis with a high rate of recurrence and peritoneal involvement; in the TCGA the EBV subgroup had the best prognosis, whereas the GS was linked with poor outcomes [8]. Finally, the esophageal TCGA found that esophageal adenocarcinoma shares much of the biology of CIN GC and this can be considered part of a biological continuum [9].

However, these molecular classifications have not found application in everyday clinical practice yet, and there is a lack of biomarkers able to individualize treatment for patients with GC, according to the concept of precision medicine.

Based on these assumptions, this review aims to summarize the current status of prognostic and predictive biomarkers evaluated in GC and their role as a guide for treatment in the era of precision medicine.

\section{Human Epidermal Growth Factor Receptor 2: the First Step in Molecularly Tailored Therapy}

Human epidermal growth factor receptor 2 (HER2) was the first validated biomarker for upper gastrointestinal tumors. HER2 overexpression in GC is related to the location of the primary tumor, with higher rates observed in gastroesophageal junction cancers (24-32\%) than in distal tumors (9.5-18\%). Additionally, the likelihood of overexpression is also associated with the tumor histological subtype; there is a prevalence in Lauren's intestinal type, especially if well or moderately differentiated, while there is a lower rate in diffuse tumors $(16-34 \%$ vs. $6-7 \%$, respectively) [10].

The phase III ToGA represents a landmark trial for HER2 in GC. This study randomized 594 patients with gastroesophageal cancer and HER2 overexpression (defined as HER2 3+ at immunohistochemistry [IHC] analysis or fluorescent in situ hybridization [FISH]-positive tumors regardless of IHC) to receive a doublet chemotherapy with cisplatin and fluorouracil/capecitabine alone or in association with trastuzumab - a humanized antibody directed against the extracellular domain of the HER2 receptor [11]. The trial demonstrated statistically significant improvements in overall survival (OS; 13.8 vs. 11.1 months, $\mathrm{HR}=0.74 ; p=0.0046$ ), response rate ( $47 \mathrm{vs}$. $35 \%$ ), and progression-free survival (PFS; 6.7 vs. 5.5 months, $\mathrm{HR}=0.71, p=0.0002)$ with the addition of trastuzumab, especially in the subgroup with a high expression of the protein (HER2 3+ at IHC or 2+ IHC with FISH amplification, median OS $=16$ vs. 11.8 months in low-HER2-expressing patients). Based on these post hoc subgroup analyses, trastuzumab was approved in many countries in addition to the cisplatin-fluoropyrimidine doublet, representing the standard of care in the first-line treatment for patients with HER2-positive disease [2]. Additionally, several trials are currently investigating the efficacy of anti HER2 agents in the adjuvant and neoadjuvant settings for HER2 positive GC [12-15]; one of them, i.e., the PETRARCA study, has suggested improved pathological complete response rates for neoadjuvant chemotherapy and HER2 directed therapy [15].

Of interest, a recently published phase II trial showed promising results by combining chemotherapy and trastuzumab with the immune checkpoint inhibitor pembrolizumab as first-line treatment for HER2-positive metastatic GC patients [16]. The trial (open label, single center, and non-randomized) involved 37 patients who were not selected for programmed death ligand 1 (PDL1); the study demonstrated a $75 \%$ PFS rate at 6 months and the median PFS and OS were 13 and 27.3 months, respectively. Of note, response rates were impressive, with a disease control rate (DCR) and overall response rate (ORR) of 100 and $91 \%$; these results are among the highest rates of response reported in the field of metastatic GC until now. Basing on these intriguing results, the phase 3 randomized KEYNOTE 811 trial is currently ongoing (NCT03615326).

Unfortunately, until now trastuzumab has remained the only anti-HER 2 targeted therapy approved globally for metastatic GC, because all subsequent trials testing the efficacy of other anti-HER2 agents in the metastatic setting, such as lapatinib, pertuzumab, and trastuzumab emtansine (TDM-1), have failed [17-20]. One of the possible reasons for this failure is that HER2 expression in GC is heterogeneous, which has implications for the efficacy of targeted therapy [21]. Additionally, HER2 expression is also dynamic in many cases. For example, Pietrantonio et al. [22] analyzed biopsy samples from 22 GC patients at baseline and post-progression after treatment including trastuzumab. The analysis showed clearly that the HER2 status changed, with a loss of overexpression in $32 \%$ of the cases, suggesting that one of the mechanisms of acquired resistance to anti-HER 2 drugs could be the loss of HER2 receptor, especially for patients with $\mathrm{IHC} 2+/ \mathrm{FISH}+$. This mechanism could produce a positive selection and expansion of HER2-negative clones during the HER2 blockade. These data were confirmed also in the more recent GASTHER3 trial, in which $29.1 \%$ of tumors showed a loss of HER2 positivity in a post-progression sample [23]. Regarding primary resistance to anti-HER2 agents, the AMNESIA study evaluated a panel of genomic alterations in 
a sample of 37 patients divided into 2 cohorts ( 17 sensitive and 20 resistant to trastuzumab) [24]. The trial showed that the lack of response to trastuzumab was mainly linked to the coexistence of epithelial growth factor receptor (EGFR)/MET/KRAS/PIK3CA/PTEN mutations or EGFR/MET/KRAS amplification (AMNESIA panel: $55 \%$ of resistant vs. $0 \%$ of sensitive). Patients with HER2 $\mathrm{ICH} 2+$ tumors showed a higher rate of resistance alterations compared to those with HER2 3+ tumors (58.3 vs. $16.7 \% ; p=0.028)$. These results underline the need to acquire a biopsy in HER2-positive patients who have progressed after first-line treatment.

Recently, novel anti-HER2 agents have been evaluated. Trastuzumab deruxtecan is an antibody drug conjugate, which has a high cytotoxic payload, a strong bystander effect, and activity in HER2-low tumors [25]. A phase I trial evaluated its safety in HER2-positive solid tumors and showed promising results in heavily pretreated HER2-positive GC patients who had already received a trastuzumab-based treatment [26]. A recently published randomized phase II trial in Asian patients confirmed these interesting data in HER2-positive GC patients who received at least 2 previous line of chemotherapy, including trastuzumab [27]. The trial randomized 187 patients between the trastuzumab deruxtecan arm and physician's choice (irinotecan or paclitaxel monotherapy), reporting better outcomes in the experimental arm $(\mathrm{ORR}=51$ vs. $14 \% ; p<0.001 ;$ median $\mathrm{OS}=12.5$ vs 8.4 months, $\mathrm{HR}=0.59 ; p=0.01$ ).

Finally, the role of HER2 as a prognostic factor is still controversial. Although retrospective studies and metaanalyses have demonstrated that HER2 overexpression represents a poor prognostic marker linked to an increased risk of invasion, metastasis, and a worse survival [28], others have found no association between HER2 expression and prognosis [29].

\section{Molecular Biomarkers and Immunotherapy}

Immunotherapy is an effective treatment choice in many types of cancers [30]. In GC, the role of immune checkpoint agents has been investigated in several trials in the metastatic setting, and other trials are ongoing in non-metastatic disease [31]. A detailed description of these studies is not the aim of this review; however, it is important to underline that, even if the trials outside of the chemorefractory disease setting have had controversial results regarding the efficacy of immunotherapy in GC, they have consistently demonstrated durable responses in selected subgroups of patients. Therefore, finding validated biomarkers able to predict the treatment response to immune checkpoint blockade has become one of the main goals in this field.
Among the possible drivers identified in the context of the molecular classifications [6-7], MSI/mismatch repair deficiency (MMRD) and EBV are undoubtedly considered the most promising biomarkers for immunotherapy in GC today [32].

Regarding MSI and MMRD, the first evidence regarding their prognostic and predictive role came from the exploratory analysis of the MAGIC trial [33], which showed that patients with non-metastatic MSI-high (MSI-H) GC had a better prognosis after surgery compared to those with MSI-low (MSI-L) or stable (MSS) disease. However, MSI-H patients had a worse prognosis when treated with perioperative chemotherapy (median $\mathrm{OS}=9.6$ months in MSI-H/MMRD vs. 19.5 months in MSS/MSI-L; HR $=2.18 ; p=0.03$ ), also showing no major pathological responses to chemotherapy. A recent comprehensive meta-analysis evaluating the data of $>1,500$ non-metastatic GC patients randomized in 4 phase III randomized trials of adjuvant and perioperative treatment strongly confirmed the positive prognostic and negative predictive roles of MSI [34]. The authors reported that patients with an MSI-H tumor had a better 5-year disease-free survival (DFS: 71.8 vs. 52.3\%) and 5-year OS (77.5 vs. 59.3\%) compared to those with MSS disease. Additionally, perioperative chemotherapy had a detrimental effect on MSI patients compared to surgery alone (5-year DFS $=70$ vs. $77 \%$; 5 -year OS $=75$ vs. $83 \%$ ), suggesting that MSI status might guide the choice of treatment in the non-metastatic setting at diagnosis [35]. In the metastatic setting, increasing evidence in many types of cancer, including GC, are recognizing the role of MSI as a predictive biomarker able to select patients who are likely to respond to immunotherapy $[36,37]$. This evidence led to the licensing of pembrolizumab (a humanized anti PD-1 antibody) by the FDA as the first tumor-agnostic therapy that may be used in every kind of solid tumor with an MSI-H status [4].

Research has also focused on the role of EBV as a predictive biomarker in GC. In particular, a phase 2 Korean trial evaluating the activity of pembrolizumab in a cohort of heavily pretreated metastatic GC patients showed - for the first time in this field - very impressive response rates in patients with MSI-H or EBV-positive tumors (ORR = $85.7 \%$ in MSI-H and $100 \%$ in EBV-positive tumors; mutually exclusive) [38]. A recently published analysis investigated the association between GC molecular subtypes and response to chemo- and immunotherapy in 410 metastatic patients [39]. It found that EBV was positive in $4.1 \%$ of tumors, and it reported a PFS of 6 months and an ORR of $62 \%$ for EBV-positive patients after first-line chemotherapy, whereas there was no difference in the efficacy of second-line chemotherapy according to molecular subtype. Of note, the PFS and ORR in EBV-positive patients who received immunotherapy as late-line treat- 
Table 1. Prognostic and predictive value of PD-L1 expression in metastatic GC patients treated within immunotherapy trials

\begin{tabular}{|c|c|c|c|c|c|c|c|c|}
\hline Trial & $\begin{array}{l}\text { Phase, line } \\
\text { of treatment, } \\
\text { population }\end{array}$ & Treatment & $\begin{array}{l}\text { Selection } \\
\text { by PD-L1 }\end{array}$ & $\begin{array}{l}\text { PD-L1 } \\
\text { expression } \\
\text { test }\end{array}$ & $\begin{array}{l}\text { PD-L1 } \\
\text { cut-off }\end{array}$ & $\begin{array}{l}\text { PD-L1 } \\
\text { patients, \% }\end{array}$ & Outcomes & $\begin{array}{l}\text { Association between } \\
\text { PD-L1 expression and } \\
\text { outcome }\end{array}$ \\
\hline \multicolumn{9}{|c|}{ Presented as a paper in extenso } \\
\hline Attraction $2[72]$ & $\begin{array}{l}3 \\
\geq 3^{\text {rd }} \text { line, } \\
\text { Asian }\end{array}$ & $\begin{array}{l}\text { Nivolumab } \\
\text { BSC }\end{array}$ & Unselected & $\begin{array}{l}\text { IHC } \\
\text { (available in 39\% } \\
\text { of patients) }\end{array}$ & $\begin{array}{l}\geq 1 \% \text { on } \\
\text { tumor cells }\end{array}$ & $\begin{array}{l}\text { Pos: } 13.5 \\
\text { Neg: } 86.4\end{array}$ & $\begin{array}{l}\text { mOS: } 5.26 \text { vs. } 4.14 \text { months; } \\
\text { mPFS: } 1.61 \text { vs. } 1.45 \text { months; } \\
\text { ORR: } 11.2 \text { vs. } 0 \% \text {; } \\
\text { DCR: } 40.3 \text { vs. } 25 \%\end{array}$ & $\begin{array}{l}\text { PD-L1-positive mOS: } \\
5.22 \text { vs. } 3.83 \text { months; } \\
\text { PD-L1-negative mOS: } \\
6.05 \text { vs. } 4.19 \text { months }\end{array}$ \\
\hline Javelin 300 [73] & $\begin{array}{l}3 \text {, } \\
\geq 3^{\text {rd }} \text { line, } \\
\text { Asian and } \\
\text { Western }\end{array}$ & $\begin{array}{l}\text { Avelumab } \\
\text { Investigator's choice }{ }^{\mathrm{a} /} \\
\text { BSC }\end{array}$ & Unselected & $\begin{array}{l}\text { IHC } \\
\text { (available in 85\% } \\
\text { of patients) }\end{array}$ & $\begin{array}{l}\geq 1 \% \text { on } \\
\text { tumor cells }\end{array}$ & $\begin{array}{l}\text { Pos: } 22.9 \\
\text { Neg: } 62.5\end{array}$ & $\begin{array}{l}\text { mOS: } 4.6 \text { vs. } 5.0 \text { months; } \\
\text { mPFS: } 1.4 \text { vs. } 2.7 \text { months; } \\
\text { ORR: } 2.2 \text { vs. } 4.3 \%\end{array}$ & $\begin{array}{l}\text { PD-L1-positive mOS: } \\
4 \text { vs. } 4.5 \text { months; } \\
\text { PD-L1-negative mOS: } \\
4.6 \text { vs. } 5.3 \text { months }\end{array}$ \\
\hline Keynote 059 [74] & $\begin{array}{l}2, \\
\geq 3^{\text {rd }} \text { line, } \\
\text { Asian and } \\
\text { Western }\end{array}$ & Pembrolizumab & Unselected & $\begin{array}{l}\text { IHC } \\
\text { (available in } \\
99.2 \% \text { of patients) }\end{array}$ & $\begin{array}{l}\geq 1 \% \text { on } \\
\mathrm{CPS}^{\mathrm{b}}\end{array}$ & $\begin{array}{l}\text { Pos: } 57.1 \\
\text { Neg: } 42.1\end{array}$ & $\begin{array}{l}\text { mOS: } 5.6 \text { months; } \\
\text { mPFS: } 2 \text { months; } \\
\text { ORR: } 11.6 \% \text {; DCR: } 27 \%\end{array}$ & $\begin{array}{l}\text { PD-L1-positive ORR: } \\
22.7 \%(2.7 \% \text { CR); } \\
\text { PD-L1-negative ORR: } \\
8.6 \%(3.4 \% \text { CR })\end{array}$ \\
\hline Keynote $061[75]$ & $\begin{array}{l}3, \\
2^{\text {nd }} \text { line, } \\
\text { Asian and } \\
\text { Western }\end{array}$ & $\begin{array}{l}\text { Pembrolizumab } \\
\text { Paclitaxel }\end{array}$ & $\begin{array}{l}\text { Unselected } \rightarrow \\
\text { PD-L1 positive }\end{array}$ & $\begin{array}{l}\text { IHC } \\
\text { (available in } \\
99.6 \% \text { of patients) }\end{array}$ & $\begin{array}{l}\geq 1 \% \text { on } \\
\text { CPS }\end{array}$ & $\begin{array}{l}\text { Pos: } 66.5 \\
\text { Neg: } 32.5\end{array}$ & $\begin{array}{l}\text { PD-L1 CPS } \geq 1 \% \\
\text { mOS: } 9.1 \text { vs. } 8.3 \text { months; } \\
\text { PD-L1 CPS } \geq 1 \% \\
\text { mPFS: } 1.5 \text { vs. } 4.1 \text { months; } \\
\text { PD-L1 CPS } \geq 1 \% \\
\text { ORR: } 16 \% \text { vs. } 14 \%\end{array}$ & $\begin{array}{l}\text { PD-L1 CPS } \geq 10 \% \text { mOS: } \\
10.4 \text { vs. } 8 \text { months; } \\
\text { PD-L1 CPS-negative mOS: } \\
4.8 \text { vs. } 8.2 \text { months }\end{array}$ \\
\hline \multicolumn{9}{|c|}{ Presented as abstract or oral presentation } \\
\hline Keynote 062 [76] & $\begin{array}{l}3, \\
1^{\text {st }} \text { line, } \\
\text { Asian and } \\
\text { Western }\end{array}$ & $\begin{array}{l}\text { Pembrolizumab } \\
\text { Pembrolizumab+ } \\
\mathrm{CF} / \mathrm{X} \\
\mathrm{CF} / \mathrm{X}\end{array}$ & PD-L1 positive & $\begin{array}{l}\text { IHC } \\
\text { (available in } \\
100 \% \text { of patients) }\end{array}$ & $\begin{array}{l}\geq 1 \% \text { on } \\
\text { CPS }\end{array}$ & Pos: 100 & $\begin{array}{l}\text { PD-L1 CPS } \geq 1 \% \text { mOS: } \\
\text { pembrolizumab was not } \\
\text { inferior to CF } / \mathrm{X} \\
\text { PD-L1 CPS } \geq 10 \% \text { mOS: } \\
\text { pembrolizumab was } \\
\text { superior to CF } / X \text {; } \\
\text { mOS and } \mathrm{mPFS} \text { were comparable } \\
\text { among association arms }\end{array}$ & $\begin{array}{l}\text { PD-L1 CPS } \geq 1 \% \text { mOS: } \\
10.6 \text { (pembro) vs. } 11.1 \\
\text { months (CF/X); } \\
\text { PD-L1 CPS } \geq 10 \% \text { mOS: } \\
17.4 \text { (pembro) vs. } \\
10.8 \text { months (CF/X) } \\
\text { regardless of PD-L1 CPS }\end{array}$ \\
\hline Javelin 100 [77] & $\begin{array}{l}3, \\
1^{\text {st line, }} \\
\text { maintenance, } \\
\text { Asian and } \\
\text { Western }\end{array}$ & $\begin{array}{l}\text { Avelumab } \\
\text { Folfox }\end{array}$ & Unselected & IHC & $\begin{array}{l}\geq 1 \% \text { on } \\
\text { tumor cells; } \\
\geq 1 \% \text { on CPS } \\
\text { (exploratory) }\end{array}$ & $\begin{array}{l}\text { Pos: } 10.8 \\
\text { Pos: } 64.3 \\
\text { Neg: } 35.6\end{array}$ & $\begin{array}{l}\text { mOS: } 10.4 \text { vs. } 10.9 \text { months; } \\
\text { ORR: } 13.3 \text { vs. } 14.4 \%\end{array}$ & $\begin{array}{l}\text { PD-L1-positive mOS: } \\
16.2 \text { vs. } 17.7 \text { months; } \\
\text { PD-L1-positive mOS: } \\
14.9 \text { vs. } 11.6 \text { months }\end{array}$ \\
\hline
\end{tabular}

${ }^{a}$ Irinotecan/paclitaxel. ${ }^{b}$ Defined as the number of PD-L1-positive cells (tumor cells, lymphocytes, and macrophages) as a proportion of the total number of tumor cells multiplied by 100. Pos, positive; Neg negative; mOS, median OS; mPFS, median PFS; BSC, best supportive care; CF/X, cisplatin and 5-fluorouracil/capecitabine; Folfox, 5-fluorouracil and oxaliplatin.

ment were 3.7 months and $33 \%$, respectively; these values are less than suggested in the previous Korean study.

The role of PD-L1 as a predictive or prognostic biomarker in GC has been controversial. Regarding the prognosis, although some trials and meta-analyses have suggested that patients with high PD-L1 expression levels have worse outcomes $[40,41]$, others have not confirmed this data [31]. Additionally, there is no consensus on PD-L1 testing in terms of antibody or site of measurement (tumor compartment or immune cells), resulting in a lack of validation. On the other hand, the predictive role of PD-L1, based on the landmark immunotherapy trials, is variable (Table 1). PD-L1 expression (combined proportion score; CPS $\geq 1$ ) is a selection biomarker for treatment with pembrolizumab in chemorefractory GC in the USA but not for nivolumab in Asian patients. Higher levels of PD-L1 expression have been associated with higher response rates and improved OS with pembrolizumab in randomized controlled trials (Table 1), but even in high-level PD-L1expressing tumors (CPS $\geq 10$ ) in the KEYNOTE-062 trial, the response rates were modest (25\%) and the PFS was inferior to those achieved with chemotherapy. PD-L1 is a modestly positive predictive biomarker for pembrolizumab efficacy but a better negative predictor.
The tumor mutational burden (TMB) reflects the load of neoantigens expressed on the tumor cells, which can stimulate the patient's immune response against cancer. Based on this concept, TMB became an important biomarker explored in several types of cancers [42]. In GC, the majority of cases have a low TMB level, while the highest levels are recorded in patients with MMRD. A recent retrospective monocentric analysis of 63 metastatic GC patients treated with immunotherapy showed that a high TMB (14.31 mutations/megabase; $12.7 \%$ of samples) was significantly associated with older age, MSI-H, PDL1, and ORR and it was linked to a higher PFS compared to a low TMB $(p=0.002)$. In particular, the MSI-H subtype had the highest median TMB (21.92 mutations/ megabase) and the highest ORR to immunotherapy $(83.3 \%)$ [43]. Interestingly, a post hoc analysis of the negative KEYNOTE-061 second-line trial of pembrolizumab versus chemotherapy suggested that patients with a high TMB (10 mutations/megabase or greater) who were MSS had high response rates to pembrolizumab (40\%) and better survival with pembrolizumab than with chemotherapy [44]. Finally, a comprehensive analysis of DNA damage response (DDR) gene alterations and TMB in 17,486 gastrointestinal tumors (including 1,750 GC) 
showed an association between DDR defects (27\% of GC), a high TMB (5.2\% of GC), and MSI-H (4.4\% of GC). However, even in patients with MSS tumors a correlation between DDR alterations and a high TMB was reported [45]. Therefore, TMB represents an intriguing field of research also in GC, as it may also enrich for sensitivity to DDR inhibitor drugs as well as immunotherapy

\section{The Role of Circulating Tumor DNA}

Over the last decade, the role of circulating tumor DNA (ctDNA) detected through a liquid biopsy has been well defined in colorectal cancer [46, 47]. In particular, ctDNA allows a non-invasive method to define the tumor's molecular profile, monitor the tumor response to treatment, or monitor relapse following surgery and to consider the impact of tumor heterogeneity [48-51]. For example, when a liquid biopsy was used to detect HER2 overexpression in metastatic GC patients, concordance with HER2 tissue results was demonstrated in only $28 \%$ of cases [52]. Therefore, although detection of a molecular alteration in ctDNA can provide useful information, it should be used in a complementary manner to tissue biopsy rather than to replace it.

In the prognostic GC setting, several groups have shown in small datasets that a positive detection of ctDNA after a curative resection for early-stage cancer is linked to a poor prognosis and a higher risk of relapse [53]. For example, a recently published analysis evaluated ctDNA after preoperative treatment from 50 resectable GC patients included in the CRITICS trial [54], distinguishing within cDNA the tumor-specific alterations (ctDNA) from the hematopoietic ones. Patients who were ctDNA positive after surgery had a shorter median eventfree survival (18.7 months vs. not reached [NR]; $p<0.001$, $\mathrm{HR}=21.8)$, a higher risk of relapse, and a worse OS (28.7 months vs. NR; $p<0.001, \mathrm{HR}=21.8$ ) [55]. However, even if ctDNA could be a promising prognostic factor for resectable GC and a tool to select patients for targeted therapy in the metastatic setting, it requires further prospective validation in larger datasets before its use as a standard of care. Additionally, novel tools are in development for measurement of tumor exosomes and miRNA in plasma, which may be fruitful in the future.

\section{Radiological and Pathological Biomarkers for Response during Perioperative Treatment}

Perioperative treatment represents the standard of care for non-metastatic GC in Western countries, but there are no validated clinical biomarkers able to predict the response before or during the treatment. In this con- text, the role of 18-fluorodeoxyglucose positron emission tomography (18-FDG-PET) scan and tumor regression grade (TRG) has been investigated.

The phase 2 MUNICON trial evaluated 18-FDG-PET scan after the first cycle of perioperative chemotherapy for non-metastatic GC in order to distinguish between metabolic responder (a decrease of $\geq 35 \%$ in the standardized uptake value compared to the 18-FDG-PET at diagnosis) and non-responding patients [56]. The study demonstrated a higher OS in metabolic responders (NR vs. 25.8 months; $p=0.015$ ), which suggested that 18 -FDGPET could be a feasible instrument to guide treatment in this setting. Following this, the MUNICON 2 trial attempted to improve the outcome of non-responders by using a salvage neoadjuvant radiochemotherapy after an induction period with chemotherapy, whereas the responders received the standard neoadjuvant treatment [57]. The trial reported an increase in histopathologic response after salvage treatment in the non-responders, although the prognosis of this group of patients was poor ( 2 -year OS rate $=42$ vs. $71 \%$ in the responder group; $p=$ $0.10 ; 1$-year PFS rate $=57$ vs. $74 \%$, respectively; $p=0.035$ ). The study did not meet its primary endpoint (increase in curative resections in the responders; $p=0.51$ ) and the trial suggests that 18 -FDG-PET scan could be more useful as a prognostic too than as a predictive one.

Recently, a phase 2 multicenter trial evaluated 18-FDGPET scan after 1 cycle of doublet chemotherapy in patients with resectable gastroesophageal tumors [58]. Patients showing a metabolic response (according to the MUNICON criteria) [56] received another cycle of doublet chemotherapy followed by surgery, whereas patients without a metabolic response were randomized to receiving 2 cycles of triplet chemotherapy or concomitant triplet chemotherapy plus radiotherapy, either followed by surgery. The trial showed better outcomes in the metabolic responders, suggesting a potential predictive role for 18-FDG-PET. Additionally, in the non-responders group the best outcomes were reached by using a chemoradiotherapy combination (36-month PFS $=47$ vs. 29 vs. $46 \%$; 60 -month OS $=53$ vs. 31 vs. $46 \%$ for responders, non-responders to chemotherapy, and non-responders to the combination, respectively), although this was associated with higher levels of toxicity.

Regarding the prognostic and predictive roles of pathology, TRG was historically considered as surrogate biomarker of survival, reflecting the response to neoadjuvant treatment. However, recent data has shown that the presence of lymph node metastasis after a preoperative chemotherapy and surgery was the only independent prognostic factor for these patients, leading to reconsideration of the assumptions surrounding TRG [59]. Finally, although Lauren histotypes represent a well-known prognostic factor in GC with a worse survival in the dif- 
fuse subtype [60], recent data has demonstrated that perioperative chemotherapy is effective for this subgroup of patients $[3,61]$. The preliminary results of the phase 2 PRODIGE-19 trial [61], which randomized 83 patients with resectable signet ring cell GC to receiving perioperative treatment or surgery followed by adjuvant chemotherapy, demonstrated that both modalities are effective (2-year OS $=53.5$ and $60 \%$, respectively). Secondly, the subgroup analysis in the phase 3 FLOT-4 trial showed a benefit with perioperative treatment for signet ring cells tumors [3]. Therefore, the Lauren subtype should not be used to select patients for perioperative chemotherapy or upfront surgery in resectable GC.

\section{Future Perspectives}

Progress in immunotherapy has underlined that the tumor microenvironment plays a key role in the chemotherapy sensitivity in several types of gastrointestinal cancer [62]. In GC, there is an active cross-talk between different cells acting in the microenvironment, such as tumor-infiltrated lymphocyte, macrophages, neutrophils, and fibroblasts. These interactions can modulate the genetic and epigenetic changes in the extracellular matrix, leading to differential responses to chemotherapy and cancer progression $[63,64]$. In particular, some trials have reported a better prognosis in patients with high CD8+ T cell levels and fewer FOXP3+ regulatory T cells and in patients with a low neutrophil-to-lymphocyte ratio [65] or platelet-to-lymphocyte ratio [66], in particular in metastatic GC treated with chemotherapy.

Regarding non-metastatic GC, a recent study developed a validated prognostic and predictive gene expression assay, which could guide the selection of patients for postoperative chemotherapy [67]. The test was based on analysis of the expression of 4 genes on an Asian retrospective tissue collection, i.e., GZMB and WARS (expression of the immune pattern), SFRP4 (stem-like pattern), and CDX1 (intestinal epithelial pattern). The authors subsequently validated the test in a cohort of patients from the CLASSIC trial [68]. The patients were divided into the following 3 prognostic groups: low (immunehigh), intermediate (immune-low and stem-like-low), and high risk (immune-low and stem-like-high); only patients in the high-risk group appeared to benefit from adjuvant treatment. However, these findings need to be prospectively confirmed.

Finally, although HER2 remains the only current validated target for biological treatment in GC, clinical trials that molecularly characterize GC patients into selected targeted therapies may represent a hope for new drug development. In this regard, the PANGEA trial evaluated a platform to select target molecular alterations for each patient in order to use personalized antibody therapy for gastroesophageal carcinomas [69]. In this project, each patient was treated with a different antibody according to their molecular characteristics (MSI-high, PD-L1 CPS >10, TMB count, EBV positive, HER2 positive, EGFR amplified, fibroblastic growth factor receptor 2 [FGFR2] amplified, MET amplified, RAS-like, EGFR expressing, All-negative). The preliminary phase 2 results demonstrated an encouraging 69.4\% 1-year OS $(p<0.001)$ with a median OS of 16.4 months by using a personalized approach. Of note, a molecular analysis of patients involved in the PANGEA trial underlined the huge role of intratumour heterogeneity between primary lesion and metastatic tissue samples [70]. Based on this "precision medicine" concept, several trials focusing on the research of molecular biomarkers and target therapies in GC are now ongoing (e.g., EGFR-target: NCT01813253, FGFR-target: NCT03343301 (FIGHT trial), multitarget vascular endothelial growth factor receptor: NCT02773524 (INTEGRATE), and claudin 18.2 target: NCT03504397 and NCT03653507). Similarly, the Viktory umbrella trial categorized 715 metastatic GC patients into 8 groups according to different biomarkers (RAS aberration, TP53 mutation, PIK3CA mutation/amplification, MET amplification, MET overexpression, All negative, TSC2 deficient, or RICTOR amplification) in order to select patients for second-line targeted treatment [71]. The results of the study showed that patients treated with tailored treatments had better outcomes compared to those treated with standard second-line therapy, providing hope for a precision targeted approach in the future.

\section{Conclusion}

GC is a heterogeneous disease; an improved understanding regarding predictive and prognostic biomarkers represents an unmet need in GC precision medicine. HER2 and MSI represent the only predictive molecular biomarkers currently validated. 18-FDG-PET scan could be useful as predictive tool in non-metastatic GC patients receiving a perioperative approach, while the role of histology is still under debate. Rigorous evaluations of the role of TMB, EBV, and ctDNA through standardized testing as well as the design of prospective randomized trials are urgently required to improve outcomes for GC patients.

\section{Disclosure Statement}

A.P. reports personal fees from Eli Lilly outside of the submitted work. E.C.S. reports personal fees from Astellas, Astra Zeneca, Five Prime, Bristol-Myers Squibb, Celgene, Gritstone Oncology, Merck, Servier, and Zymeworks outside of the submitted work. 


\section{Funding Sources}

This paper received no funding.

\section{Author Contributions}

A.P. and E.C.S. conceived the idea, performed the research, and wrote this paper.

\section{References}

1 Bray F, Ferlay J, Soerjomataram I, Siegel RL, Torre LA, Jemal A. Global cancer statistics 2018: GLOBOCAN estimates of incidence and mortality worldwide for 36 cancers in 185 countries. CA Cancer J Clin. 2018 Nov;68(6): 394-424.

2 Smyth EC, Verheij M, Allum W, Cunningham D, Cervantes A, Arnold D; ESMO Guidelines Committee. Gastric cancer: ESMO Clinical Practice Guidelines for diagnosis, treatment and follow-up. Ann Oncol. 2016 Sep;27 suppl 5:v38-49.

3 Al-Batran SE, Homann N, Pauligk C, Goetze TO, Meiler J, Kasper S, et al.; FLOT4-AIO Investigators. Perioperative chemotherapy with fluorouracil plus leucovorin, oxaliplatin, and docetaxel versus fluorouracil or capecitabine plus cisplatin and epirubicin for locally advanced, resectable gastric or gastro-oesophageal junction adenocarcinoma (FLOT4): a randomised, phase 2/3 trial. Lancet. 2019 May;393(10184):1948-57.

4 US Federal Drug Administration. Hematology/oncology (cancer) approvals \& safety notifications. Available from: https://www.fda. gov/drugs/resources-information-approveddrugs/hematologyoncology-cancer-approvals-safety-notifications.

5 Tirino G, Pompella L, Petrillo A, Laterza MM, Pappalardo A, Caterino M, et al. What's New in Gastric Cancer: The Therapeutic Implications of Molecular Classifications and Future Perspectives. Int J Mol Sci. 2018 Sep; 19(9):E2659.

6 Bass AJ, Thorsson V, Shmulevich I, Reynolds SM, Miller M, Bernard B, et al. Cancer Genome Atlas Research Network. Comprehensive molecular characterization of gastric adenocarcinoma. Nature. 2014;513(7517):2029

7 Cristescu R, Lee J, Nebozhyn M, Kim KM, Ting JC, Wong SS, et al. Molecular analysis of gastric cancer identifies subtypes associated with distinct clinical outcomes. Nat Med. 2015 May;21(5):449-56.

8 Cancer Genome Atlas Research NetworkAnalysis Working Group. Asan University; BC Cancer Agency. Integrated genomic characterization of oesophageal carcinoma. Nature. 2017;541(7636):169-75.

9 Sohn BH, Hwang JE, Jang HJ, Lee HS, Oh SC, Shim JJ, et al. Clinical Significance of Four Molecular Subtypes of Gastric Cancer Identified by The Cancer Genome Atlas Project. Clin Cancer Res. 2017 Jul;23(15):4441-9.

10 Lordick F, Al-Batran SE, Dietel M, Gaiser T, Hofheinz RD, Kirchner T, et al. HER2 testing in gastric cancer: results of a German expert meeting. J Cancer Res Clin Oncol. 2017 May; 143(5):835-41.

11 Bang YJ, Van Cutsem E, Feyereislova A, Chung HC, Shen L, Sawaki A, et al.; ToGA Trial Investigators. Trastuzumab in combination with chemotherapy versus chemothera- py alone for treatment of HER2-positive advanced gastric or gastro-oesophageal junction cancer (ToGA): a phase 3, open-label, randomised controlled trial. Lancet. 2010 Aug; 376(9742):687-97.

12 Wagner AD, Grabsch HI, Mauer M, Marreaud S, Caballero C, Thuss-Patience P, et al. EORTC-1203-GITCG - the "INNOVATION"-trial: Effect of chemotherapy alone versus chemotherapy plus trastuzumab, versus chemotherapy plus trastuzumab plus pertuzumab, in the perioperative treatment of HER2 positive, gastric and gastroesophageal junction adenocarcinoma on pathologic response rate: a randomized phase II-intergroup trial of the EORTC-Gastrointestinal Tract Cancer Group, Korean Cancer Study Group and Dutch Upper GI-Cancer group. BMC Cancer. 2019 May;19(1):494.

13 Rivera F, Jimenez-Fonseca P, Alfonso PG, Gallego J, Limon ML, Lopez-Gomez MA, et al. NEOHX study: Perioperative treatment with trastuzumab in combination with capecitabine and oxaliplatin (XELOX-T) in patients with HER 2 resectable stomach or esophagogastricjunction (EGJ) adenocarcinoma-18 m DFS analysis. J Clin Oncol. 2015;33(Suppl 3):107.

14 Hofheinz R, Hegewisch-Becker S, Thuss-Patience P, Kunzmann V, Fuchs M, Ullrich Graeven U, et al. HER-FLOT: Trastuzumab in combination with FLOT as perioperative treatment for patients with HER2-positive locally advanced esophagogastric adenocarcinoma: A phase II trial of the AIO Gastric Cancer Study Group. J Clin Oncol. 2014;32(Suppl 15):4073.

15 Hofheinz RD, Haag GM, Ettrich TJ, Borchert K, Kretzschmar A, Teschendorf C et al. Perioperative trastuzumab and pertuzumab in combination with FLOT versus FLOT alone for HER2-positive resectable esophagogastric adenocarcinoma: Final results of the PETRARCA multicenter randomized phase II trial of the AIO. J Clin Oncol. 2020;38:15_ suppl:4502.

16 Janjigian YY, Maron SB, Chatila WK, Millang B, Chavan SS, Alterman C, et al. First-line pembrolizumab and trastuzumab in HER2positive oesophageal, gastric, or gastro-oesophageal junction cancer: an open-label, single-arm, phase 2 trial. Lancet Oncol. 2020 Jun; 21(6):821-31.

17 Tabernero J, Hoff PM, Shen L, Ohtsu A, Shah MA, Cheng K, et al. Pertuzumab (P) + Trastuzumab (H) + Chemotherapy (CT) for, H.E.R2-Positive Metastatic Gastric or GastroOesophageal Junction Cancer (mGC/GEJC): Final Analysis of a Phase III Study (JACOB). Ann Oncol. 2017;28:v209-68.

18 Thuss-Patience PC, Shah MA, Ohtsu A, Van Cutsem E, Ajani JA, Castro H, et al. Trastuzumab emtansine versus taxane use for previously treated HER2-positive locally advanced or metastatic gastric or gastro-oesophageal junction adenocarcinoma (GATSBY): an international randomised, open-label, adaptive, phase 2/3 study. Lancet Oncol. 2017 May; 18(5):640-53.

19 Hecht JR, Bang YJ, Qin SK, Chung HC, Xu JM, Park JO, et al. Lapatinib in Combination With Capecitabine Plus Oxaliplatin in $\mathrm{Hu}$ man Epidermal Growth Factor Receptor 2-Positive Advanced or Metastatic Gastric, Esophageal, or Gastroesophageal Adenocarcinoma: TRIO-013/LOGiC-A Randomized Phase III Trial. J Clin Oncol. 2016 Feb;34(5): 443-51.

20 Satoh T, Xu RH, Chung HC, Sun GP, Doi T, $\mathrm{Xu}$ JM, et al. Lapatinib plus paclitaxel versus paclitaxel alone in the second-line treatment of HER2-amplified advanced gastric cancer in Asian populations: TyTAN-a randomized, phase III study. J Clin Oncol. 2014 Jul;32(19): 2039-49.

21 Wakatsuki T, Yamamoto N, Sano T, Chin K, Kawachi H, Takahari D, et al. Clinical impact of intratumoral HER2 heterogeneity on trastuzumab efficacy in patients with HER2positive gastric cancer. J Gastroenterol. 2018 Nov;53(11):1186-95.

22 Pietrantonio F, Caporale M, Morano F, Scartozzi M, Gloghini A, De Vita F, et al. HER2 loss in HER2-positive gastric or gastroesophageal cancer after trastuzumab therapy: implication for further clinical research. Int J Cancer. 2016 Dec;139(12):2859-64.

23 Seo S, Ryu MH, Park YS, Ahn JY, Park Y, Park SR, et al. Loss of HER2 positivity after antiHER2 chemotherapy in HER2-positive gastric cancer patients: results of the GASTric cancer HER2 reassessment study 3 (GASTHER3). Gastric Cancer. 2019 May;22(3):527-35.

24 Pietrantonio F, Fucà G, Morano F, Gloghini A, Corso S, Aprile G, et al. Biomarkers of Primary Resistance to Trastuzumab in HER2Positive Metastatic Gastric Cancer Patients: the AMNESIA Case-Control Study. Clin Cancer Res. 2018 Mar;24(5):1082-9.

25 Tsurutani J, Iwata H, Krop I, Jänne PA, Doi T, Takahashi $S$ et al. Targeting HER2 with Trastuzumab Deruxtecan: A Dose-Expansion, Phase I Study in Multiple Advanced Solid Tumors. Cancer Discov. 2020 May;10(5): 688-701.

26 Shitara K, Iwata H, Takahashi S, Tamura K, Park H, Modi S, et al. Trastuzumab deruxtecan (DS-8201a) in patients with advanced HER2-positive gastric cancer: a dose-expansion, phase 1 study. Lancet Oncol. 2019 Jun; 20(6):827-36

27 Shitara K, Bang YJ, Iwasa S, Sugimoto N, Ryu MH, Sakai D, et al.; DESTINY-Gastric01 Investigators. Trastuzumab Deruxtecan in Previously Treated HER2-Positive Gastric Cancer [published online ahead of print, 2020 May 29]. N Engl J Med. 2020 Jun;382(25): 2419-30. 
28 Lei YY, Huang JY, Zhao QR, Jiang N, Xu HM, Wang ZN, et al. The clinicopathological parameters and prognostic significance of HER2 expression in gastric cancer patients: a metaanalysis of literature. World J Surg Oncol. 2017 Mar;15(1):68.

29 Kim H, Seo S, Kim K, Park YH, An M, Baik $\mathrm{H}$, et al. Prognostic significance of Human epidermal growth factor receptor-2 expression in patients with resectable gastric adenocarcinoma. World J Surg Oncol. 2019 Jul; 17(1):122.

30 Pham T, Roth S, Kong J, Guerra G, Narasimhan V, Pereira L, et al. An Update on Immunotherapy for Solid Tumors: A Review. Ann Surg Oncol. 2018 Oct;25(11):3404-12.

31 Jones JO, Smyth EC. Gastroesophageal cancer: navigating the immune and genetic terrain to improve clinical outcomes. Cancer Treat Rev. 2020 Mar;84:101950.

32 Martinez-Ciarpaglini C, Fleitas-Kanonnikoff T, Gambardella V, Llorca M, Mongort C, Mengual R, et al. Assessing molecular subtypes of gastric cancer: microsatellite unstable and Epstein-Barr virus subtypes. Methods for detection and clinical and pathological implications. ESMO Open. 2019 May;4(3):e000470.

33 Smyth EC, Wotherspoon A, Peckitt C, Gonzalez D, Hulkki-Wilson S, Eltahir Z, et al. Mismatch Repair Deficiency, Microsatellite Instability, and Survival: An Exploratory Analysis of the Medical Research Council Adjuvant Gastric Infusional Chemotherapy (MAGIC) Trial. JAMA Oncol. 2017 Sep;3(9):1197-203.

34 Pietrantonio F, Miceli R, Raimondi A, Kim YW, Kang WK, Langley RE, et al. Individual Patient Data Meta-Analysis of the Value of Microsatellite Instability As a Biomarker in Gastric Cancer. J Clin Oncol. 2019 Dec; 37(35):3392-400

35 Smyth EC. Chemotherapy for resectable microsatellite instability-high gastric cancer? Lancet Oncol. 2020 Feb;21(2):204.

36 National Comprehensive Cancer Network. Clinical practice guidelines in oncology: gastric cancer. 2019. Available from: http://www. nccn.org/professionals/physician_gls/pdf/ gastric.pdf.

37 Petrillo A, Tirino G, Zito Marino F, Pompella L, Sabetta R, Panarese I, et al. Nivolumab in Heavily Pretreated Metastatic Gastric Cancer Patients: Real-Life Data from a Western Population. OncoTargets Ther. 2020 Jan;13:86776.

38 Kim ST, Cristescu R, Bass AJ, Kim KM, Odegaard JI, Kim K, et al. Comprehensive molecular characterization of clinical responses to PD-1 inhibition in metastatic gastric cancer. Nat Med. 2018 Sep;24(9):1449-58.

39 Kubota Y, Kawazoe A, Sasaki A, Mishima S, Sawada K, Nakamura Y, et al. The impact of molecular subtype on efficacy of chemotherapy and checkpoint inhibition in advanced gastric cancer. Clin Cancer Res. 2020 Jul; 26(14):3784-90.

40 Zhang M, Dong Y, Liu H, Wang Y, Zhao S, Xuan Q, et al. The clinicopathological and prognostic significance of PD-L1 expression in gastric cancer: a meta-analysis of 10 studies with 1,901 patients. Sci Rep. 2016 Nov;6(1): 37933.
41 Gu L, Chen M, Guo D, Zhu H, Zhang W, Pan $\mathrm{J}$, et al. PD-L1 and gastric cancer prognosis: A systematic review and meta-analysis. PLoS One. 2017 Aug;12(8):e0182692.

42 Smolle E, Leithner K, Olschewski H. Oncogene addiction and tumor mutational burden in non-small-cell lung cancer: clinical significance and limitations. Thorac Cancer. 2020 Feb;11(2):205-15.

43 Kim J, Kim B, Kang SY, Heo YJ, Park SH, Kim ST et al. Tumor Mutational Burden Determined by Panel Sequencing Predicts Survival After Immunotherapy in Patients With Advanced Gastric Cancer. Front Oncol. 2020 Mar; 10:314.

44 Shitara K, Özgüroğlu M, Bang YJ, Di Bartolomeo M, Mandalà M, Ryu MH, et al. The association of tissue tumor mutational burden (tTMB) using the Foundation Medicine genomic platform with efficacy of pembrolizumab versus paclitaxel in patients (pts) with gastric cancer (GC) from KEYNOTE-061. J Clin Oncol. 2020;38(suppl; abstr 4537).

45 Parikh AR, He Y, Hong TS, Corcoran RB, Clark JW, Ryan DP, et al. Analysis of DNA Damage Response Gene Alterations and Tumor Mutational Burden Across 17,486 Tubular Gastrointestinal Carcinomas: implications for Therapy. Oncologist. 2019 Oct;24(10): 1340-7.

46 Tarazona N, Gimeno-Valiente F, Gambardella V, Zuñiga S, Rentero-Garrido P, Huerta M, et al. Targeted next-generation sequencing of circulating-tumor DNA for tracking minimal residual disease in localized colon cancer. Ann Oncol. 2019 Nov;30(11):1804-12.

47 Tie J, Wang Y, Tomasetti C, Li L, Springer S, Kinde I, et al. Circulating tumor DNA analysis detects minimal residual disease and predicts recurrence in patients with stage II colon cancer. Sci Transl Med. 2016 Jul;8(346): $346 \mathrm{ra} 92$.

48 Corcoran RB, Chabner BA. Application of Cell-free DNA Analysis to Cancer Treatment. N Engl J Med. 2018 Nov;379(18):1754-65.

49 Lee, JY, Francovic A, Shiotsu Y, Kim ST, Kim KM, Banks KC, Detection of ERBB2 (HER2) Gene Amplification Events in Cell-Free DNA and Response to Anti-HER2 Agents in a Large Asian Cancer Patient Cohort. Front Oncol. 2019 Apr;9:212.

50 Wang Y, Zhao C, Chang L, Jia R, Liu R, Zhang $\mathrm{Y}$, et al. Circulating tumor DNA analyses predict progressive disease and indicate trastuzumab-resistant mechanism in advanced gastric cancer. EBioMedicine. 2019 May;43:2619.

51 Liu Y, Yang M, Jiang T, Lan C, Yuan H, Li G, et al. Quantitative Analysis of HER2 Amplification by Droplet Digital PCR in the FollowUp of Gastric Cancer Patients Being Treated with Trastuzumab after Surgery. Gastroenterol Res Pract. 2019 Jan;2019:1750329.

52 Maron SB, Chase LM, Lomnicki S, Kochanny S, Moore KL, Joshi SS, et al. Circulating Tumor DNA Sequencing Analysis of Gastroesophageal Adenocarcinoma. Clin Cancer Res. 2019 Dec;25(23):7098-112.

53 Frankell AM, Smyth EC. ctDNA in Gastric and Gastroesophageal Cancer: Prognostic, Predictive, or Preliminary? Clin Cancer Res. 2019 Dec;25(23):6893-5.
54 Cats A, Jansen EP, van Grieken NC, Sikorska $\mathrm{K}$, Lind $\mathrm{P}$, Nordsmark $\mathrm{M}$, et al.; CRITICS investigators. Chemotherapy versus chemoradiotherapy after surgery and preoperative chemotherapy for resectable gastric cancer (CRITICS): an international, open-label, randomised phase 3 trial. Lancet Oncol. 2018 May;19(5):616-28.

55 Leal A, van Grieken NC, Palsgrove DN, Phallen J, Medina JE, Hruban C, et al. White blood cell and cell-free DNA analyses for detection of residual disease in gastric cancer. Nat Commun. 2020 Jan;11(1):525.

56 Lordick F, Ott K, Krause BJ, Weber WA, Becker K, Stein HJ, et al. PET to assess early metabolic response and to guide treatment of adenocarcinoma of the oesophagogastric junction: the MUNICON phase II trial. Lancet Oncol. 2007 Sep;8(9):797-805.

57 zum Büschenfelde CM, Herrmann K, Schuster T, Geinitz H, Langer R, Becker K, et al. (18) F-FDG PET-guided salvage neoadjuvant radiochemotherapy of adenocarcinoma of the esophagogastric junction: the MUNICON II trial. J Nucl Med. 2011 Aug;52(8):1189-96.

58 Barbour AP, Walpole ET, Mai GT, Barnes EH, Watson DI, Ackland SP, et al.; DOCTOR investigators. Preoperative cisplatin, fluorouracil, and docetaxel with or without radiotherapy after poor early response to cisplatin and fluorouracil for resectable oesophageal adenocarcinoma (AGITG DOCTOR): results from a multicentre, randomised controlled phase II trial. Ann Oncol. 2020 Feb;31(2): 236-45.

59 Smyth EC, Fassan M, Cunningham D, Allum WH, Okines AF, Lampis A, et al. Effect of Pathologic Tumor Response and Nodal Status on Survival in the Medical Research Council Adjuvant Gastric Infusional Chemotherapy Trial. J Clin Oncol. 2016 Aug;34(23): 2721-7.

60 Petrelli F, Berenato R, Turati L, Mennitto A, Steccanella F, Caporale M, et al. Prognostic value of diffuse versus intestinal histotype in patients with gastric cancer: a systematic review and meta-analysis. J Gastrointest Oncol. 2017 Feb;8(1):148-63.

61 Eveno C, Adenis A, Bouche O, Le Malicot K, Hautefeuille V, Faroux R, et al. Adjuvant chemotherapy versus perioperative chemotherapy (CTx) for resectable gastric signet ring cell (SRC) gastric cancer: A multicenter, randomized phase II study (PRODIGE 19). J Clin Oncol. 2019 May;37(15):4019.

62 Solinas C, Pusole G, Demurtas L, Puzzoni M, Mascia R, Morgan G, et al. Tumor infiltrating lymphocytes in gastrointestinal tumors: controversies and future clinical implications. Crit Rev Oncol Hematol. 2017 Feb;110:10616.

63 Rojas A, Araya P, Gonzalez I, Morales E. Gastric Tumor Microenvironment. Adv Exp Med Biol. 2020;1226:23-35.

64 Gambardella V, Castillo J, Tarazona N, Gimeno-Valiente F, Martínez-Ciarpaglini C, Cabeza $\mathrm{M}$, et al. The role of Tumor-Associated Macrophages in Gastric Cancer development and their potential as a therapeutic target. Cancer Treat Rev. 2020 Jun;86:102015. 
65 Petrillo A, Laterza MM, Tirino G, Pompella L, Ventriglia J, Pappalardo A, et al. Systemic-inflammation-based score can predict prognosis in metastatic gastric cancer patients before first-line chemotherapy. Future Oncol. 2018 Oct;14(24):2493-505.

66 Cao W, Yao X, Cen D, Zhi Y, Zhu N, Xu L. The prognostic role of platelet-to-lymphocyte ratio on overall survival in gastric cancer: a systematic review and meta-analysis. BMC Gastroenterol. 2020 Jan;20(1):16.

67 Cheong JH, Yang HK, Kim H, Kim WH, Kim YW, Kook MC, et al. Predictive test for chemotherapy response in resectable gastric cancer: a multi-cohort, retrospective analysis. Lancet Oncol. 2018 May;19(5):629-38.

68 Bang YJ, Kim YW, Yang HK, Chung HC, Park YK, Lee KH, et al.; CLASSIC trial investigators. Adjuvant capecitabine and oxaliplatin for gastric cancer after D2 gastrectomy (CLASSIC): a phase 3 open-label, randomised controlled trial. Lancet. 2012 Jan;379(9813): 315-21.

69 Catenacci DVT, Lomnicki S, Chase L, Peterson B, Moore K, Markevicius U, et al. Personalized ANtibodies for GastroEsophageal Adenocarcinoma (PANGEA): Primary efficacy analysis of the phase II platform trial (NCT02213289). J Clin Oncol. 2020;38(4 Suppl):356
70 Pectasides E, Stachler MD, Derks S, Liu Y, Maron S, Islam M, et al. Genomic Heterogeneity as a Barrier to Precision Medicine in Gastroesophageal Adenocarcinoma. Cancer Discov. 2018 Jan;8(1):37-48.

71 Lee J, Kim ST, Kim K, Lee H, Kozarewa I, Mortimer PG, et al. Tumor Genomic Profiling Guides Patients with Metastatic Gastric Cancer to Targeted Treatment: The VIKTORY Umbrella Trial. Cancer Discov. 2019 Oct; 9(10):1388-405.

72 Kang YK, Boku N, Satoh T, Ryu MH, Chao Y, Kato K, et al. Nivolumab in patients with advanced gastric or gastro-oesophageal junction cancer refractory to, or intolerant of, at least two previous chemotherapy regimens (ONO4538-12, ATTRACTION-2): a randomised, double-blind, placebo-controlled, phase 3 trial. Lancet. 2017 Dec;390(10111):2461-71.

73 Bang YJ, Ruiz EY, Van Cutsem E, Lee KW, Wyrwicz L, Schenker M, et al. Phase III, randomised trial of avelumab versus physician's choice of chemotherapy as third-line treatment of patients with advanced gastric or gastro-oesophageal junction cancer: primary analysis of JAVELIN Gastric 300. Ann Oncol. 2018 Oct;29(10):2052-60.
74 Bang YJ, Kang YK, Catenacci DV, Muro K, Fuchs CS, Geva R, et al. Pembrolizumab alone or in combination with chemotherapy as first-line therapy for patients with advanced gastric or gastroesophageal junction adenocarcinoma: results from the phase II nonrandomized KEYNOTE-059 study. Gastric Cancer. 2019 Jul;22(4):828-37.

75 Shitara K, Özgüroğlu M, Bang YJ, Di Bartolomeo $\mathrm{M}$, Mandalà $\mathrm{M}$, Ryu $\mathrm{MH}$, et al.; KEYNOTE-061 investigators. Pembrolizumab versus paclitaxel for previously treated, advanced gastric or gastro-oesophageal junction cancer (KEYNOTE-061): a randomised, open-label, controlled, phase 3 trial. Lancet. 2018 Jul;392(10142):123-33.

76 Tabernero J, Van Cutsem E, Bang YJ, Fuchs CS, Wyrwicz L, Lee KW, et al. Pembrolizum$\mathrm{ab}$ with or without chemotherapy versus chemotherapy for advanced gastric or gastroesophageal junction adenocarcinoma: the phase III KEYNOTE-062 study. ASCO Annual Meeting; 2019 Jun 2.

77 Moehler MH, Dvorkin M, Ozguroglu M, Ryu $\mathrm{MH}$, Muntean AS, Lonardi S et al. Results of the JAVELIN Gastric 100 phase III trial: Avelumab maintenance following first-line chemotherapy vs continuation of chemotherapy for HER2-advanced gastric or gastroesophageal junction cancer. Gastrointestinal Cancers Symposium; 2020 Jan 23 